\title{
HUBUNGAN PAROXYSMAL NOCTURNAL DYSPNEA (PND) DENGAN KUALITAS TIDUR PADA PASIEN CONGESTIVE HEART FAILURE(CHF) DI RUANG PENYAKIT DALAM RSUD HASANUDDIN DAMRAH MANNA
}

\section{Relationship Betwen Paroxismal Noctural Dyspepnea (PND) And Sleep Quality In Congestive Heart Failure (CHF) Patients In Internal Medicine Room Hasanuddin Damrah Hospital Manna}

\author{
Neni Triana ${ }^{1}$, Hanifah ${ }^{2}$,Intan Purnama Susila ${ }^{3}$ \\ ${ }^{1}$ Program Studi Ilmu Keperawatan STIKES Tri Mandiri Sakti Bengkulu \\ Email: neni triananers@yahoo.co.id
}

\begin{abstract}
ABSTRAK
Paroxysmal Nocturnal Dyspnea (PND) merupakan sesak napas pada malam hari selang beberapa jam ketika pasien tertidur sehingga dapat mempengaruhi kualitas tidur seseorang. Tujuan penelitian ini untuk mempelajari hubungan PND dengan kualitas tidur pada pasien CHF di ruang penyakit dalam RSUD Hasanuddin Damrah Manna.Jenis Penelitian ini adalah penelitian kuantitatif dengan desain cross-sectional.Populasi adalah seluruh pasien CHF di ruang penyakit dalam RSUD Hasanuddin Damrah Manna.Sampel diambil menggunakan teknik accidental sampling yang berjumlah 35 orang.Data yang digunakan adalah data primer dan data sekunder.Analisis data menggunakan uji Exact Fisher's dengan hasil p-value $=0,004<0,05$ dan uji Contingency Coefficient (C)dengan hasil $\mathrm{C}=0,459$. Hasil penelitian didapatkan dari 35 pasien terdapat $21(60 \%)$ mengalami PND, 23 (65,7\%) dengan kualitas tidur buruk, ada hubungan PND dengan kualitas tidur pada pasien CHF di ruang penyakit dalam RSUD Hasanuddin Damrah Manna dengan kategori hubungan erat. Diharapkan tenaga kesehatan dapat memberikan intervensi non farmakologis, seperti positioning dengan posisi tidur semi fowler, sebagai alternatif untuk mengurangi PND dalam meningkatkan kualitas tidur pada pasien CHF.
\end{abstract}

Kata Kunci: Congestive Heart Failure (CHF), Paroxysmal Nocturnal Dyspnea (PND), kualitas tidur

\section{ABSTRACT}

Paroxysmal Nocturnal Dyspnea (PND) is shortness of breath at night lapse of several hours when the patient is asleep so that it can affect one's sleep quality. The purpose of this study was to study the relationship of PND with sleep quality in CHF patients in the internal medicine room at Hasanuddin Damrah Hospital Manna. This type of research is a quantitative study with crosssectional design. The population was all CHF patients in the internal medicine room at Hasanuddin Damrah Manna Hospital. Samples were taken using accidental sampling technique, amounting to 35 people. The data used are primary data and secondary data. Data analysis used the Fisher's Exact test with the results of p-value $=0.004<0.05$ and the Contingency Coefficient (C) test with the results of $C=0.459$. The results obtained from 35 patients there were $21(60 \%)$ experienced PND, 23 (65.7\%) with poor sleep quality, there was a relationship of PND with sleep quality in CHF patients in the disease room in Hasanuddin Damrah Manna Hospital with close relationship category. It is expected that health workers can provide non-pharmacological interventions, such as positioning with a semi-sleeping position, as an alternative to reducing PND in improving sleep quality in CHF patients.

Keywords: Congestive Heart Failure (CHF), Paroxysmal Nocturnal Dyspnea (PND), sleep quality

PENDAHULUAN 
Masalah kesehatan dengan gangguan sistem kardiovaskuler termasuk didalamnya Congestive Heart Failure (CHF) masih menduduki peringkat yang tinggi, menurut data World Health Organization (WHO) pada tahun 2007 dilaporkan bahwa gagal jantung mempengaruhi lebih dari 20 juta pasien di dunia dan meningkat seiring pertambahan usia dan mengenai pasien dengan usia lebih dari 65 tahun, sekitar 6-10\% lebih banyak mengenai laki-laki dari pada wanita. Pada tahun 2030 (WHO) memprediksi peningkatan penderita gagal jantung mencapai 23 juta jiwa di dunia (Sudoyo, 2008).

Menurut Sudoyo (2006), penyakit gagal jantung adalah penyakit sindrom klinis yang ditandai oleh sesak nafas dan fatique saat istirahat atau saat aktivitas yang disebabkan oleh kelainan struktur atau fungsi jantung. Parker (2008) mengemukakan bahwa terdapat 5 (lima) gejala yang paling umum ditemukan pada pasien dengan gagal jantung yaitu dyspnea (85,2\%), fatique $(84,9 \%)$, mulut kering $(74,1 \%)$, ngantuk sepanjang hari $(67,9 \%)$, dan kesulitan untuk tidur $(64,2 \%)$. Diantara gejala-gejala tersebut kesulitan untuk tidur dan fatique dilaporkan sebagai gejala yang tidak bisa ditoleransi.Sehubungan dengan ini, Parker (2008) menyebutkan bahwa gangguan tidur pada pasien dengan gagal jantung sangat mempengaruhi kualitas hidupnya.

Menurut Sudoyo (2008), penyakit gagal jantung menimbulkan berbagai gejala klinis yang dirasakan klien beberapa diantaranya dispnea, ortopnea, paroxysmal nocturnal dispnea (PND) sesak napas pada malam hari yang sebelumnya duduk lama dengan posisi kaki dan tangan di bawah, kemudian berbaring ke tempat tidur sehingga tekanan sirkulasi paru meningkat dan lebih lanjut, cairan berpindah ke alveoli. Gejala lain yang muncul adanya keluhan mudah lelah akibat meningkatnya energi yang digunakan untuk bernapas dan insomnia (gangguan tidur) yang terjadi akibat distress pernapasan dan batuk. Keluhan gelisah dan cemas pada klien terjadi akibat gangguan oksigenasi jaringan. Stress pada klien diakibatkan oleh adanya kesakitan saat bernapas dan pengetahuan bahwa jantung tidak berfungsi dengan baik.

Berbagai gejala pada klien gagal jantung akan mengganggu kebutuhan dasar manusia. Gangguan kebutuhan dasar pada klien gagal jantung tersebut akan menimbulkan masalah keperawatan, salah satu diantaranya adalah sleep deprivation/ disturbed sleep pattern berhubungan dengan nocturia atau sleep position because nocturnal dyspnea. Sleep deprivation adalah periode lama yang tidak bisa tidur secara alami dan terus menerus dalam periode kesadaran relatif. Sedangkan disturbed sleep pattern adalah keterbatasan waktu tidur secara alami dan terus menerus dalam periode kesadaran relatif meliputi jumlah dan kualitas. Kebutuhan tidur merupakan bagian dari hidup yang dibutuhkan (Amin Huda, 2015).

Gagal jantung sebagai masalah medis dapat mengakibatkan gangguan tidur disamping penyebab lain, diantaranya perubahan usia normal, masalah psikiatri dan psikososial. Tanpa jumlah istirahat dan tidur yang cukup, kemampuan untuk berkonsentrasi, membuat keputusan dan berpartisipasi dalam aktivitas harian atau keperawatan akan menurun dan meningkatkan iritabilitas (Potter \& Perry, 2005).

Gangguan istirahat tidur pada klien gagal jantung terutama terjadi pada malam hari karena sesak napas sangat mengganggu kualitas dan kuantitas tidur klien. Kualitas tidur yang buruk mengakibatkan proses perbaikan kondisi klien akan semakin lama sehingga akan memperpanjang long of stay (LOS) di rumah sakit. Lamanya perawatan ini akan menambah beban biaya yang ditanggung klien menjadi tinggi dan kemungkinan akan menimbulkan respon hospitalisasi bagi klien. Satu teori fungsi tidur sangat berhubungan dengan penyembuhan (Potter \& Perry, 2005).

Dari sisi keperawatan itu sendiri dimana jika seseorang memperoleh tidur yang cukup, mereka merasa tenaganya telah pulih.Memperoleh kualitas tidur terbaik adalah penting untuk peningkatan kesehatan yang baik dan pemulihan klien yang sakit.Klien yang sakit seringkali membutukan lebih banyak tidur dan istirahat daripada klien yang sehat. Sifat alamiah dari penyakit akan mengurangi klien mendapatkan istirahat dan tidur yang cukup (Potter \& Perry, 2005).

Berdasarkan studi pendahuluan (survey awal) yang didapat dari medical record 
rumah sakit Hasanuddin Damrah Manna kasus congestive heart failure (CHF) dari tahun ke tahun mengalami peningkatan. Tahun 2016 berjumlah 260 orang, tahun 2017 berjumlah 345 orang dan pada tahun 2018 berjumlah 422 orang. Berdasarkan uraian di atas dan mengingat begitu bayak permasalahan yang muncul pada pasien CHF, dari perubahan gaya hidup, kadar kolesterol yang tinggi, perokok aktif dan kurangnya kesadaran berolahraga menjadi faktor pemicu munculnya penyakit gagal jantung.

Rumusan masalah dalam penelitian ini adalah apakah ada hubungan paroxysmal nocturnal dyspnea (PND) dengan kualitas tidur pada pasien congestive heart failure (CHF) di ruang penyakit dalam RSUD Hasanuddin Damrah Manna. Tujuan penelitianini adalah untuk mempelajari hubungan paroxysmal nocturnal dyspnea (PND) dengan kualitas tidur pada pasien congestive heart failure (CHF) di ruang penyakit dalam RSUD Hasanuddin Damrah Manna.

\section{METODE PENELITIAN}

Penelitian ini menggunakan pendekatan Cross-Sectional. Populasi adalah seluruh pasien CHF di ruang penyakit dalam RSUD Hasanuddin Damrah Manna.Sampel diambil menggunakan teknik accidental sampling yang berjumlah 35 orang. Data yang digunakan adalah data primer dengan menggunakan kuesioner untuk penilaian kualitas tidur dan observasi untuk PND.Data dianalisis menggunakan analisis univariat dan bivariat dengan uji Exact Fisher's dan uji Contingency Coefficient (C).

\section{HASIL PENELITIAN}

1. Analisis Univariat

Analisis univariat dilakukan untuk memperoleh gambaran distribusi frekuensi dari variabel independen (paroxysmal nocturnal dyspnea (PND)) dan variabel dependen (Kualitas tidur) di ruang penyakit dalam RSUD Hasanuddin Damrah. Hasil analisis univariat dapat dilihat pada tabeltabel berikut:

Tabel 1. Gambaran Distribusi Frekuensi PNDpada Pasien CHF di Ruang Penyakit Dalam RSUD Hasanuddin Damrah MannaTahun 2019

\begin{tabular}{cccc}
\hline No & PND & Frekuensi & Persentase(\%) \\
\hline 1 & PND & 21 & 60,0 \\
2 & Tidak PND & 14 & 40,0 \\
\hline 3 & Total & 35 & 100,0 \\
\hline
\end{tabular}

Berdasarkan Tabel 1 menunjukkan bahwa dari 35 responden (100\%), yang menderita CHF terdapat 21 responden $(60 \%)$ mengalami paroxysmal nocturnal dyspnea (PND) dan terdapat 14 responden (40\%) tidak mengalami paroxysmal nocturnal dyspnea (PND).

Tabel 2. Gambaran Distribusi Frekuensi Kualitas Tidur pada Pasien CHF di Ruang Penyakit Dalam RSUD Hasanuddin Damrah Manna Tahun2019

\begin{tabular}{cccc}
\hline No & Kualitas tidur & Frekuensi & Persentase(\%) \\
\hline 1 & Baik & 12 & 34,3 \\
2 & Buruk & 23 & 65,7 \\
\hline 4 & Total & 35 & 100,0 \\
\hline
\end{tabular}

Berdasarkan Tabel 2 menunjukkan bahwa dari 35 responden $(100 \%)$ yang menderita CHF terdapat 12 responden $(34,3 \%)$ yang kualitas tidurnya baik dan 23 responden $(65,7 \%)$ yang kualitas tidurnya buruk.

2. Analisis Bivariat

Analisis bivariat dilakukan dengan menggunakan Fisher's Exact Test untuk mengetahui hubungan antara variabel independen dengan variable dependen yaitu hubungan paroxysmal nocturnal dyspnea (PND) dengan kualitas tidur pada pasien congestive heart failure (CHF) di ruang penyakit dalam RSUD Hasanuddin Damrah Mannadapat dilihat pada tabel berikut: 
Tabel 4.4 Hubungan PND dengan Kualitas Tidur pada Pasien CHF di Ruang Penyakit Dalam RSUD Hasanuddin Damrah Manna Tahun 2019

\begin{tabular}{cccccc}
\hline \multirow{2}{*}{ PND } & \multicolumn{3}{c}{ Kualitas Tidur } & \multirow{2}{*}{$P$} & \multirow{2}{*}{$\mathrm{C}$} \\
\cline { 2 - 4 } & Baik & Buruk & Total & & \multirow{2}{*}{0.004} \\
\hline PND & 3 & 18 & 21 & \multirow{2}{*}{0,459} \\
Tidak PND & 9 & 5 & 14 & 0,004 & \\
\hline Total & 12 & 23 & 35 & & \\
\hline
\end{tabular}

Berdasarkan Tabel 3terlihat bahwa dari 21 orang yang mengalami PND terdapat 3 orang $(14,3 \%)$ dengan kualitas tidur baik dan 18 orang $(85,7 \%)$ dengan kualitas tidur buruk, dan dari 14 orang tidak PND terdapat 9 orang $(64,3 \%)$ dengan kualitas tidur baik dan 5 orang $(35,7 \%)$ dengan kualitas tidur buruk.

Hasil ujiExact Fisher'sdidapat nilai pValue $=0,004<0,05$ berarti signifikan, maka Ho ditolak dan Ha diterima. Jadi ada hubunganparoxysmal nocturnal dyspnea (PND) dengan kualitas tidur Hasil uji Contingency Coefficient didapat nilai $\mathrm{C}=$ 0,459 dengan $p$-value $=0,005<0,05$ berarti signifikan, dengan kategori hubunngan erat.

\section{PEMBAHASAN}

Berdasarkan hasil penelitian, lebih dari sebagian atau 21 responden $(60 \%)$ mengalami paroxysmal nocturnal dyspnea (PND). Hal ini menunjukkan Pasien CHF lebih dari sebagian mengalami paroxysmal nocturnal dyspnea (PND). Pada saat dilakukan penelitian, banyak pasien CHF yang mengalami sesak pada malam hari sehingga pasien terbangun dari tidurnya. Sesak terjadi selang beberapa jam setelah pasien tertidur, gejala PND yang dialami yaitu nafas menjadi pendek, keringat dingin, batuk kadang disertai dengan mengi. Duduk atau meninggikan kepala dilakukan pasien untuk membuka jalan nafas. Upaya-upaya yang dapat dilakukan pasein CHF untuk mengurangi sesak akibat PND salah satunya adalah pengaturan posisi yang baik dan benar. Posisi yang dapat mengurangi PND yaitu dengan meninggikan bagian kepala menggunakan bantal atau posisi semi fowler.

Setelah pernafasan menjadi normal kembali, PND memerlukan 10-30 menit atau lebih lama untuk hilang. Jika duduk atau meninggikan kepala tidak menghentikan gejala, pasien harus segera menghubungi perawat untuk medapatkan perawatan lebih lanjut.

Hasil penelitian tersebut sejalan dengan pendapat Udjianti (2015), yang menyatakan bahwa CHF atau yang sering dikenal dengan (gagal jantung) adalah penyebab paling serius paroxysmal nocturnal dyspnea(PND) yaitu sesak napas pada malam hari yang mungkin muncul tibatiba dan menyebabkan penderita terbangun. PND muncul setelah beberapa jam pasien tertidur. Sesak nafas biasanya akan membaik dengan perubahan posisi tidur 20-30 derajat atau semi fowler.

Berdasarkan hasil penelitian terdapat lebih dari sebagian atau ada 23 responden $(65,7 \%)$ yang kualitas tidurnya buruk. Pada saat penelitian berlangsung, pasien $\mathrm{CHF}$ cendrung mengalami kualitas tidur yang buruk, karena pasien sering terbangun pada malam hari yaitu dari kuesioner nomor 5 banyak pasien yang memiliki skor 2-3. Lebih dari sebagian pasien mengalami sesak setelah beberapa jam ketika mereka tertidur atau sekitar pukul 00.00 s.d 01.00 wib dengan durasi 10 menit bahkan ada yang sampai 30 menit. Paroxysmal nocturnal dyspnea(PND) mengakibatkan pasien terbangun pada malam hari, PND diatasi dengan perubahan posisi tidur semi fowler, tetapi pasien cendrung mengalami kesulitan untuk memulai tidur kembali. PND yang mereka alami membuat beberapa dari pasien kepikiran/stres, sesak yang sebelumnya mereka alami akan timbul lagi selang beberapa jam saat mereka terlelap.

Hal ini sejalan dengan pendapat Asmadi (2008), yaitu ada beberapa faktor yang dapat mempengaruhi kualitas tidur seseorang diantaranya adalah status kesehatan (penyakit), lingkungan, stres psikologis, diet/nutrisi, gaya hidup, obatobatan, motivasi. Pasien dengan status kesehatan yang sedang terganggu misalnya seperti pada pasien dengan CHF. Berbagai 
gejala pada klien dengan gagal jantung akan mengganggu kebutuhan dasar manusia, salah satu diantaranya adalah kebutuhan dasar tidur. Kebutuhan tidur merupakan bagian dari hidup yang sangat dibutuhkan (Amin Huda, 2015).

Klien yang sakit seringkali membutuhkan lebih banyak tidur dan istirahat daripada klien yang sehat. Sifat alamiah dari penyakit akan mengurangi klien mendapatkan istirahat dan tidur yang cukup. dimana jika seseorang memperoleh tidur yang cukup, mereka merasa tenaganya telah pulih. Memperoleh kualitas tidur terbaik adalah penting untuk peningkatan kesehatan yang baik dan pemulihan klien yang sakit, khususnya pada kualitas tidur pasien congestive heart failure (CHF) (Potter \& Perry, 2005).

Dari 21 orang yang mengalami PND ada 3 orang yang kualitas tidurnya baik. Hal ini disebabkan responden tersebut mengikuti instruksi perawat/dokter, untuk mengatasi PND pada pasien CHFyaitu mempertahankan tirah baring dengan posisi tidur 20-30 derajat atau semi fowler.Tujuan dari tindakan memberikan posisi tidur adalahuntuk menurunkan konsumsi $\mathrm{O} 2$ dan meningkatkan ekspansi paru maksimal, serta untuk mengatasi kerusakan pertukaran gas yangberhubungandenganperubahanmembran kapileralveolus.Terapi keperawatan positioning dengan posisi tidur semifowler (20-30 derajat) dimaksudkan agar kerusakan membran alveolus akibat tertimbunnya cairan akanberkurang sesuai dengan gaya gravitasi sehingga $\mathrm{O} 2$ delivery menjadi optimal dan sesak napas dapat diminimalisir/tidak terjadi. Dan pada akhirnya kebutuhan dan kualitas tidur klien bisa terpenuhi sehingga proses perbaikan kondisi klien menjadi lebih cepat (Potter \& Perry, 2005).

Responden PND dengan kualitas tidur baik, pada saat penelitian mereka mampu untuk memulai tidur kembali setelah selang beberapa menit mengalami PND. Pasien ini merupakan pasien VIP dengan kondisi ruangan yang nyaman sehingga tidak membutuhkan waktu yang lama bagi mereka untuk memulai tidur kembali sehingga mereka mendapatkan kualitas tidur yang cukup/baik.

Dari 21 orang yang mengalami PND ada 18 orang yang mengalami kualitas tidur buruk. Kualitas tidur responen yang buruk disebabkan oleh beberapa alasan, seperti sesak napas yang yang terus-menerus walaupun sudah dilakukan posisi semi fowler, adanya keluhan nyeri dada, lingkungan yang tidak nyaman dan kecemasan. Kejadian PND dialami responden setelah beberapa jam tertidur.

PND dapat terjadi 1-2 kali dalam satu malam sehingga pasien yang baru terlelap dapat terbangun lagi yang mengakibatkan gangguan kualitas tidur NREM terganggu. Kualitas tidur yang buruk ini ditandai dengan lamanya waktu untuk tertidur, beberapa kali terbangun ditengah malam bahkan ada laporan responden yang menyatakan tidak tidur selama satu malam.

Kualitas tidur merupakan kemampuan individu untuk tetap tertidur dan mendapatkan jumlah tidur REM dan NREM yang tepat. Memperoleh kualitas tidur terbaik adalah penting untuk peningkatan kesehatan yang baik dan pemulihan individu yang sakit. Klien yang sakit sering kali membutuhkan lebih banyak tidur dan istirahat dari pada kalien yang sehat (Potter \& Perry, 2005)

Dari 14 orang tidak PND terdapat 5 orang $(35,7 \%)$ yang kualitas tidurnyaburuk. Pasien tidak PND tetapi kualitas tidurnya buruk, banyak faktor yang mempengaruhi kualitas tidur klien bukan hanya penyakit yang mendukung, tetapi lingkungan yang tidak kondusif sepeti pada pasien kelas 3 dengan pasien kelas 1 atau VIP dari kapasitas pasien serta lingkungan saja sudah sangat berbeda. Pasien kelas 3 dengan jumlah pasien yang banyak, adanya pengunjung yang rame/ruang rawat inap yang bising dan suhu udara yang terlalu panas akan meningkatkan stres pada pasien sehingga akan berpengaruh terhadap kulitas tidur pasien khususnya pasien CHF.

Peran serta keluarga juga sangat dibutuhkan dalam proses penyembuhan klien. Klien yang sakit sangat membutuhkan dukungan/motivasi dari keluarga. Stress pada klien dengan lingkungan rumah sakit dan proses penyakit yang dialami akan memberikan energi positif apabila mereka mendapatkan dukungan dari keluarga yang menguatkan mereka. Dukungan keluarga merupakan sikap peneriamaan terhadap keluarga yang sakit baik itu dukungan 
informasional, emosional, penghargaan maupun dukungan instrumental. Peningkatan dukungan keluarga dapat membantu pasien untuk mempertahankan kondisinya. Kondisi yang baik akan akan mencegah stres akibat penyakit yang diderita pasien (Friedman, 2013). Stres akan berdampak pada psikis klien, pada keadaan ini meningkatnya energi yang digunakan klien sehingga akan menggangu kualitas tidur klien. Hal ini sejalan dengan pendapat Potter \& Perry (2005) tanpa jumlah istirahat dan tidur yang cukup, kemampuan untuk berkonsentrasi, membuat keputusan dan berpartisipasi dalam aktivitas harian atau keperawatan akan menurun dan meningkatkan iritabilitas. Dan dari sisi keperawatan itu sendiri dimana jika seseorang memperoleh tidur yang cukup, mereka merasa tenaganya telah pulih.Memperoleh kualitas tidur terbaik adalah penting untuk peningkatan kesehatan yang baik dan pemulihan klien yang sakit.

Dari 14 orang tidak PND terdapat 9 orang $(63,4 \%)$ yang mengalami kualitas tidur baik. Pasien tidak mengalami sesak pada malam hari, nyeri dada, kecemasan, ataupun keluhan lainnya seperti lingkungan ataupun stres, sehingga membuat responden mendapatkan kualitas tidur yang baik. Ada laporan dari beberapa responden yang menyatakan walaupun terjaga dimalam hari, tapi mereka tidak mengalami kesulitan untuk memulai tidur kembali.

Salah satu faktor yang mempegaruhi kualitas tidur adalah penyakit fisik. Jadi ketika seseorang tidak mengalami keluhan fisik ataupun keluhan lainnya, pasien merasa lebih tenang dan rileks sehingga pasien dapat beristirahat lebih nyaman dan mendapatkan kesempatan untuk memperoleh kualitas tidur yang baik. Penyakit biasanya mencegah beberapa pasien untuk mendapatkan tidur dan istirahat yang adekuat(Potter \& Perry, 2010)

Menurut pendapat peneliti, ruang rawat inap merupakan salah satu wujud fasilitas fisik yang penting keberadaannya bagi pelayanan pasien. Karena itu, lingkungan yang kondusif akan sangat berdampak terhadap proses penyembuhan pasien, salah satunya seperti kebutuhan dasar tidur. Pola tidur yang baik memberikan efek yang bagus terhadap pemulihan kesehatan klien yang sedang sakit. Berdasarkan analisis bivariat diketahui hasil ujiExact Fisher's didapat nilai $\mathrm{p}$-Value $=0,004$. Yang berarti ada hubungan yang signifikan antara paroxysmal nocturnal dyspnea (PND) dengan kualitas tidur pada pasien congestive heart failure (CHF). Berdasarkan hasil tersebut dapat dijelaskan bahwa pasien congestive heart failure (CHF) dengan paroxysmal nocturnal dyspnea (PND) cendrung kualitas tidurnya akan terganggu. Hal ini diperkuat dengan kategori hubungan erat antara paroxysmal nocturnal dyspnea (PND) dengan kualitas tidurpada pasien congestive heart failure (CHF) di ruang penyakit dalam RSUD Hasanuddin Damrah Manna. Sesuai dengan hasil penelitian Nurhayati, S (2015), bahwa adanya hubungan antara paroxysmal nocturnal dyspnea (PND) dengan kualitas tidurpada pasien congestive heart failure (CHF).

Selanjutnya akan dilihat keeratan hubungan antara paroxysmal nocturnal dyspnea (PND) dengan kualitas tidur pada pasien congestive heart failure (CHF) di ruang penyakit dalam RSUD Hasanuddin Damrah Manna. Hal ini dapat dilhat dari Hasil uji Contingency Coefficient didapat keeratan hubungan antara paroxysmal nocturnal dyspnea (PND) dengan kualitas tidur pada pasien congestive heart failure (CHF) dengan kategori hubunangan erat. Berdasarkan hasil tersebut dapat dijelaskan bahwa pasien congestive heart failure (CHF) dengan paroxysmal nocturnal dyspnea (PND) cendrung kualitas tidurnya buruk.

Hal ini didukung oleh menurut pendapat Asmadi (2008), bahwa ada beberapa faktor yang dapat mempengaruhi kualitas tidur seseorang yaitu status kesehatan (penyakit), lingkungan, stres psikologis, diet/nutrisi, gaya hidup, obatobatan, motivasi.

Hal ini sesuai dengan hasil penelitian Nurhayati, S (2015) dimana terdapat hubungan yang signifikan antara paroxysmal nocturnal dyspnea (PND) dengan kualitas tidur pada pasien congestive heart failure (CHF) dengan nilai $p$ value $0,008 \%$.

Berdasarkan hasil penelitian, terdapat beberapa implikasi yang dapat digunakan untuk peningkatan dalam bidang 
keperawatan, yaitu dalam penanganannya, perawat perlu mengembangkan upaya-upaya pembaharuan penatalaksanaan secara non farmakologis agar kualitas hidup pasien congestive heart failure(CHF) semakin meningkat, institusi rumah sakit diharapkan lebih meningkatkan lagi pelayanan kesehatan khususnya perawat untuk pelayanan serta kebutuhan pasien dan dapat melakukan peningkatan fasilitas yang ada di rumah sakit seperti tempat tidur yang berstandar SNI yaitu tempat tidur baja beroda dengan pengaturan posisi, memperhatikan jumlah pasien dalam satu ruangan dengan pembatasan pengunjung. Pasien CHF diharapkan mendapat tambahan informasi tentang faktor-faktor yang mempengaruhi kualitas tidur dan upayaupaya yang dapat dilakukan untuk mendapatkan kualitas tidur yang baik.

\section{KESIMPULAN}

1. Dari 35 pasien terdapat $21(60 \%)$ pasien mengalami PND

2. Dari 35 pasien terdapat $23(65,7 \%)$ pasien dengan kualitas tidur buruk

3. Ada hubungan PND dengan kualitas tidur pada pasien CHF di ruang penyakit dalam RSUD Hasanuddin Damrah Manna dengan kategori hubungan erat.

\section{DAFTAR PUSTAKA}

Amin, H. (2015). Asuhan Keperawatan Bedasarkan Diagnoda Medis dan NANDA.Jakarta: Madiaction

Asmadi. (2008). Teknik Prosedural Keperawatan: Konsep dan Aplikasi Kebutuhan Dasar Klien. Jakarta: Salemba Medika.

Friedman. (2013). Buku Ajar Keperawatan Keluarga Riset, Teori, \& Praktik. Jakarta: ECG

Nurhayati, S. (2015).Faktor-Faktor Yang Berhubungan Dengan Kualitas Tidur Pada Pasien Congestive Heart Failure. Program Studi Ilmu Keperawatan Universitas Riau. Diperoleh pada tanggal 10 Januari 2019 dari http://universitasriau.ac.id/publikasi/ejournal/file/2016/201608-002.pdf

Parker \& Dunbar (2008).Sleep snd HeartFailure. Jakarta: Salemba Medika.
Potter, P. A., \& Perry, A. G. (2005).Fundamental Keperawatan Edisi 7. Jakarta: Salemba Medika.

Sudoyoet.al (2006). Buku Ajar Ilmu Penyakit Dalam, Jilid 2 Edisi IV. Jakarta: Pusat Penerbitan Departemen Ilmu Penyakit Dalam Fakultas Kedokteran Universutas Indonesia

Udjianti, W. J. (2010). Keperawatan Kardiovaskular. Jakarta: Salemba Medik. 